Available online at www.jmle.org

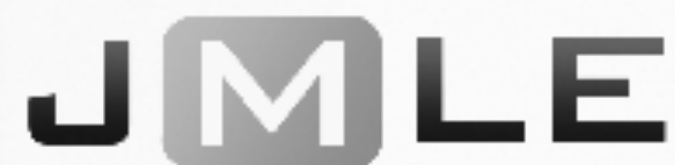

The National Association for Media Literacy Education's

Journal of Media Literacy Education 9 (2), 17 - 29

\title{
Beyond Universal Design for Learning: Guiding Principles to Reduce Barriers to Digital \& Media Literacy Competence
}

\author{
Elizabeth M. Dalton \\ University of Rhode Island
}

\begin{abstract}
Universal Design for Learning (UDL), a framework for designing instruction to address the wide range of learner variation in today's inclusive classrooms, can be applied effectively to broaden access, understanding, and engagement in digital and media literacy learning for ALL. UDL supports constructivist learning principles. UDL strategies and methods encourage development of expert learners though personal engagement and motivation. UDL transforms one-size-fits-all instruction into diverse, multiple, and accessible learning opportunities that embrace student variation. UDL principles and guidelines offer a unique way for educators in digital and media literacy fields to ensure that their work will benefit the widest range of learners, including those with learning challenges and disabilities.
\end{abstract}

Keywords: Universal Design for Learning, access, accessibility, technology, digital literacy, media literacy

It is important for all students to develop and grow as informed and reflective participants in our democratic society. To do so, all learners need not only access to content and information, but also engagement and connection to what they are learning. Development of digital and media literacy provides students with tools and contexts to better understand and personalize their connections to culture, society, and the democratic process, which often leads to greater effort and persistence in learning. As individual skills, beliefs, and experiences are challenged or affirmed by connecting to information through digital and other media sources, learners become more self-aware, expand their 
epistemic cognition, and become better able to self-regulate their own learning (Greene, Yu, \& Copeland, 2014).

My interest in curriculum design started when I pursued further education through an individualized M.Ed. program in special education and curriculum development. Having already worked as a special education teacher for five years in RI public schools, I found that many more options were needed in the pathways, approaches, methods, and materials used to vary curriculum and instruction for diverse students and their teachers. This interest led to several professional paths: an exploration into the powers of assistive technology, and later to post-doctoral studies at the Center for Applied Special Technology (CAST) and Boston College. To expand the reach of technology supports in education, I co-founded the TechACCESS Center of RI, a state and regional center for assistive technology services to persons of all ages. Additionally, I have served as board member and president of the Inclusive Learning Network of ISTE, a professional learning network focused on effective educational and assistive technologies for those with differing needs. The power of technology and Universal Design for Learning (UDL) to inform varied curriculum design and development has important implications on equity issues in digital and media literacy.

By expanding our view of literacy to include all forms of media, options for educators to represent what they are teaching and how students show what they have learned are broadened enormously. Considering and integrating the UDL curriculum design framework with the fields of digital and media literacy will ensure that learning environments and materials are accessible and engaging for all students. This article introduces the history, principles and rationale for UDL and makes specific connections between UDL principles and digital and media literacy essential competencies (Hobbs, 2010). Exemplifying the role digital and media literacy can play in the implementation of UDL to expand the capabilities of our students in today's society.

\section{What is UDL?}

Describe the typical classroom. Who is the typical learner? What does a typical learning environment look like? If you have difficulty responding, there are some very good reasons: the word typical is synonymous with terms like average, regular, standard, and normal. Who is the average student? What is normal? When we try to picture what a standard or regular classroom looks like, it is an impossible task. While the concept of standard may exist statistically, it does not exist in the reality of the classroom or other learning environments. Every student is a unique individual with different characteristics, preferences, abilities, and beliefs that deserve consideration when designing curricula and instruction. Data and statistics can be standardized, but people cannot.

Variation, rather than standardization, is the true reality of our students and it needs to be our educational reality. David Rose, one of the originators of UDL and chief education officer of the Center for Applied Special Technology (CAST) states ".... In many classrooms, the focus is on an illusory average student. Many curricula are designed for that student. Cognitive neuroscience has 
shown us that there really isn't an average student anywhere, and that's why it's an illusory student" (CAST, 2014). By recognizing the reality of learner variability, and building this variation into the design of instruction and curriculum, educators can address learners' varied needs and capabilities effectively. This concept is at the heart of the UDL conceptual framework.

Research in cognitive science and neuroscience shaped the development of UDL. Understanding how we learn through memory, language processing, perception, thinking, and problem solving is central for the effective consideration of learner variability. Research identifies three neural functions involved in cognition: a) pattern recognition, b) pattern planning and generation, and c) pattern determination of importance (Rose \& Strangman, 2007). Three specific learning components significantly impact the performance of these functions: a) recognition of information to be learned, b) application of strategies to process the information, and c) engagement in the learning task (Vygotsky, 1962).

CAST, which served originally as a technical support center for students with special needs in Massachusetts was seeking a different path to support students' growth and development, one based on capitalizing students' strengths, rather than primarily remediating weaknesses. Vygotsky's work, and others, served as the foundation for CAST's development of the conceptual framework of UDL (Meyer \& Rose, 1998; Orkwis \& McLane, 1998; Rose \& Meyer, 2002). Inspired by the earlier architectural concept of Universal Design (UD) of physical environments originally developed by the late Ron Mace (Center for Universal Design, 1997), the UDL framework for curriculum design is based on the three primary brain networks of recognition, strategy, and affect. These networks account for the broad diversity of individual learning styles, and closely correlate with the work of Vygotsky. The three core principles of UDL were developed from this foundation.

\section{The Core Principles of UDL}

CAST's research on the neurological basis of learning styles, in combination with its practical work with learners who had widely varying needs, eventually yielded the three core principles of UDL (Hall, Strangman, \& Meyer, 2003). These three principles are:

\section{Multiple Means of Representation (the HOW of learning)}

To address varied learner capabilities and needs, multiple and flexible methods of presentation of content and information are used to support recognition learning. For example, teachers can present the learning materials through a variety of media (visual, auditory, or tactile), and provide multiple examples that can be modified in complexity to meet a range of learning needs.

2. Multiple Means of Action and Expression (the WHAT of learning)

To address varied learner capabilities and needs, multiple and flexible methods of action and expression of students' learning are incorporated into instruction to support strategic learning. Teachers can use strategies that allow the learner to practice tasks with different 
levels of support and to demonstrate their knowledge and skills in a diversity of ways.

\section{Multiple Means of Engagement (the WHY of learning)}

To address varied learner capabilities and needs, multiple and flexible options for engagement in the learning process are used to support affective learning. Teachers can design and plan instruction that involves creating interesting and varied learning opportunities that motivate and stimulate learners according to their personal backgrounds and interests.

Over the years since the UDL principles were first developed, their order of presentation has been discussed, disputed, and changed. The above order is how the UDL principles were originally presented. Recently, in CAST's most recent book Universal Design for Learning: Theory and Practice (Meyer, Rose, \& Gordon, 2013), the UDL principles are reordered, putting Multiple Means of Engagement first. The rationale for this is that students' engagement must be present before students are ready to fully address learning through the other two principles of Recognition, or Action and Expression. In reality, all three UDL principles are critical for educators to address, if they seek to broaden their instruction to meet varied student learning needs and abilities through effective design.

UDL is often referred to as a front-loaded model for curriculum design. This means that curriculum variations to address learning through recognition, strategy, and affect are built into the design of the lesson from the start. This approach differs from accommodation or modification approaches for learners who have differing or special needs. When accommodations are used, or when modifications are made, these are carried out because the original curriculum design does not meet the needs of the learner, and changes in the delivery of instruction must be made. UDL changes this sequence. Instead, in the UDL framework, variations in the materials, methods, and assessment of instruction are built into the design of all lessons, units, etc., so that all students can benefit. It is a shift of focus - rather than needing to "retrofit" instruction to address individual student's differing needs, accessibility of instruction is built into the design of learning experiences. To accomplish such a shift, every educator needs consider the UDL principles in the context of their instructional environment and of the objectives, methods, materials, and assessments that are pertinent to this environment.

\section{UDL Guidelines}

To assist in designing goals, methods, materials, and assessments to make them accessible for ALL students, including those with disabilities, CAST developed a comprehensive set of guidelines for UDL consideration and implementation (CAST, 2011). These guidelines address areas within each of the UDL principles, and offer checkpoints to suggest ways in which instruction may be varied in its design for each guideline area. Currently there are nine guideline areas, three for each UDL core principle. These include: 
Multiple Means of Representation:

1) Provide options for perception

2) Provide options for language, mathematical expressions, and symbols

3) Provide options for comprehension

Multiple Means of Action \& Expression:

4) Provide options for physical action

5) Provide options for expression and communication

6) Provide options for executive functions

Multiple Means of Engagement:

7) Provide options for recruiting interest

8) Provide options for sustaining effort and persistence

9) Provide options for self-regulation

Guidance in implementing the UDL guidelines is offered through specific checkpoints associated with each guideline. For example, under the UDL principle of Multiple Means of Representation, Guideline 1 reads "Provide options for perception." Three checkpoints for this guideline are provided:

Checkpoint 1.1 Offer ways of customizing the display of information

Checkpoint 1.2 Offer alternatives for auditory information

Checkpoint 1.3 Offer alternatives for visual information.

It is up to the instructor to determine what alternatives will be most appropriate and helpful in their own instructional situation. All UDL checkpoints are elaborated through comprehensive descriptions and specific examples of what these variations can look like. For example, ways of customizing the display of information include varying the size of text, the contrast between text and background, the color used, the volume or rate of sound, the speed of video, animation, etc., and the font. These are just a few potential variations for design. The UDL guidelines, checkpoints, examples, and resources are available in great detail at www.udlcenter.org, website for the National Center on UDL. Educators seeking to understand and implement UDL in their learning environments should take advantage of these extensive resources to expand their understanding of UDL, and to design their instruction to meet the needs of all students through this innovative instructional design framework.

\section{Digital and Media Literacy, UDL, and Technology}

UDL holds great potential to establish truly accessible learning environments for all students. Successful implementation of these principles into practice, however, does not require the use of specific technology or equipment. UDL should be implemented through varied planning of goals, methods, materials, and assessments (NCUDL, 2014). UDL can be achieved through the selection of strategies that vary the paths to learning or by selecting and using 
varied materials in the design of instruction. It can be achieved through other nontechnology-related means to support the three UDL principles, however, the extensive capabilities provided by digital technology to transform information into varied formats do offer unique and powerful tools to address learner variability.

According to the American Library Association (ALA, 2016), digital literacy is "the ability to use information and communication technologies to find, evaluate, create, and communicate information, requiring both cognitive and technical skills." According to the National Association for Media Literacy Education (NAMLE, 2016), media literacy is "the ability to encode and decode the symbols transmitted via media and the ability to synthesize, analyze and produce mediated messages." Digital literacy and media literacy are often considered together, as they share several common elements: both digital literacy and media literacy involve competence in varied means of communication, and both digital literacy and media literacy involve the use of technology (whether high-tech, i.e. computers or low-tech, i.e. printed materials) in some form.

Understanding these definitions and this relationship of digital literacy and media literacy, and understanding the powerful role that technology can play in the implementation of UDL, it is logical to consider UDL in the context of digital and media literacy. When information is available and provided in digital format, it can be easily changed and enhanced. This characteristic of digital information offers significant opportunities in considering, planning, and implementing UDL in digital and/or various media environments. To explore the potential of these connections, it is appropriate to consider the current core principles of media literacy education, and the essential competencies for digital and media literacy.

Media Literacy Education:

Core Principles, Essential Competencies and UDL

Having just reviewed UDL core principles, I now turn to explain how best practices in media literacy education also follow specific core principles. These include:

1) Active inquiry and critical thinking about messages;

2) Expanding literacy to all forms of media;

3) Building and reinforcing media skills for all ages;

4) Developing informed and reflective participants in a democratic society;

5) Recognizing media as part of culture and socialization; and

6) Affirming individual skills, beliefs, and experiences in constructing personal meaning from media (NAMLE, 2016).

Several areas of these sets of core principles overlap in their intent, as UDL and media literacy education both strive to empower, enhance, and expand the capabilities of our students in today's society.

Considering the UDL core principles in relation to the NAMLE core principles, the UDL principles of Multiple Means of Representation and Multiple 
Means of Action \& Expression clearly relate to the first three NAMLE principles. Active inquiry and critical thinking is fueled by differing representations of information and content through various types of media. Active inquiry and critical thinking also leads individuals to recognize and be able to demonstrate their learning in a variety of different ways. By expanding literacy to include all forms of media, the options for how educators represent what they are teaching and the options for how students show what they have learned through the use of a variety of media are greatly expanded. By building media skills for all ages, everyone will have at hand additional tools to achieve differing means of both representing information and expressing what has been learned.

The UDL principle of Multiple Means of Engagement is supported by the NAMLE principles as well, and is evidenced in relation to the UDL checkpoints for this principle. As informed and reflective participants in a democratic society, learners have greater interest and connection to what they are learning. Understanding media as part of culture and socialization helps learners to develop a context for their learning, which leads to greater effort and persistence in learning. When individual skills, beliefs, and experiences are affirmed through the construction of personal meaning from media, learners become more self-aware and are better able to self-regulate their own learning. There are other connections that can likely be made between the two sets of principles however it is clear that these sets of principles, the UDL principles and the NAMLE principles, are mutually supportive and can help to inform development and expansion of effective instructional design to better reach all students.

\section{Challenges, Barriers, and Accessibility}

For individuals who experience challenges and/or disabilities related to learning, or to accessing learning, Section 504 of the Rehabilitation Act of 1973 has long provided guidance for the protection of individuals from discrimination based on their disability (Office of Civil Rights, 2006). Section 504 pre-dates PL 94-142 (special education law), the Americans with Disabilities Act (ADA), and the Higher Education Opportunity Act, establishing the foundation for all antidiscrimination laws that have followed. Simply stated, Section 504 "forbids organizations and employers from excluding or denying individuals with disabilities an equal opportunity to receive program benefits and services. It defines the rights of individuals with disabilities to participate in, and have access to, program benefits and services" (p. 1).

In its practical implementation, Section 504 protects the rights of individuals with disabilities by requiring that all entities that receive any form of federal funds are both physically and programmatically accessible. Section 504 impacts all levels of education. It impacts any businesses or organizations that accept federal funds. The U.S. Office of Civil Rights is the overseeing agency to ensure that equity of access is achieved for all qualified individuals with disabilities, meaning persons with physical or mental impairment that substantially limits one or more major life activities, including caring for one's self, walking, seeing, hearing, speaking, breathing, working, performing manual tasks, and learning (Office of Civil Rights, 2006). 
To address the challenges faced by individuals with disabilities to participate equally in today's society, professionals who deal with digital literacy and media literacy can find some guidance. The Higher Education Opportunity Act of 2008 guides institutions to incorporate Universal Design (UD) and UDL (as well as assistive technologies, when appropriate) in their practices by recommending and addressing UD and UDL in Section 103 of the Act (CAST 2010):

(23) UNIVERSAL DESIGN.

The term "universal design" has the meaning given the term in section 3 of the Assistive Technology Act of 1998 (29 U.S.C. 3002) [which is: "The term 'universal design' means a concept or philosophy for designing and delivering products and services that are usable by people with the widest possible range of functional capabilities, which include products and services that are directly accessible (without requiring assistive technologies) and products and services that are interoperable with assistive technologies."]

(24) UNIVERSAL DESIGN FOR LEARNING.

The term "universal design for learning" means a scientifically valid framework for guiding educational practice that:

(A) provides flexibility in the ways information is presented, in the ways students respond or demonstrate knowledge and skills, and in the ways students are engaged; and

(B) reduces barriers in instruction, provides appropriate accommodations, supports, and challenges, and maintains high achievement expectations for all students, including students with disabilities and students who are limited English proficient.

The strategic and thoughtful use of educational and assistive technologies, and appropriate strategies for their effective use, can further the implementation of UDL for many students and teachers, when used in concert with some of many other tools available to educators that can support high-quality and varied instruction (Dalton, 2005).

\section{Digital and Media Literacy Essential Competencies and Accessibility}

The context of digital and media literacy essential competencies (Hobbs, 2010) offers a way to consider issues that impact equity of access and accessibility, and to explore some examples for digital and media literacy practice.

Competency \#1. ACCESS. "Finding and using media and technology tools skillfully and sharing appropriate and relevant information with others" (Hobbs, 2010, p. 19).

The challenges that face individuals with disabilities to achieve Competency \#1 are primarily those of physical accessibility of tools and information, or the lack of it. For those who face sensory challenges, such as deafness or blindness, information that is presented in a single format may cause this information to be completely inaccessible and therefore unusable. To avoid 
this problem, access through media and technology tools can be leveraged by using tools that offer content and information in a variety of formats - visual, auditory, video, print, verbal, tactile (as with refreshable braille devices), and even through virtual reality.

Competency \#2. ANALYZE \& EVALUATE. "Comprehending messages and using critical thinking to analyze message quality, veracity, credibility, and point of view, while considering potential effects or consequences of messages" (Hobbs, 2010, p. 19).

The challenges that individuals with disabilities face to achieve Competency \#2 relate to the paths by which an individual perceives, comprehends, and then processes information. While varied means of physical access, as described for Competency \#1, can impact this path, more importantly it is learning processes such as reading and writing that come into play, and can become barriers. To address reading, writing, and other difficulties relating to comprehension, www.callscotland.org.uk offers extensive guidance. Housed at the University of Edinburgh, CALL Scotland has a wealth of resources that can be used to help overcome disability and barriers to learning that are created by the environment. Their posters and leaflets outlining tools that support reading, writing, and communication are current and comprehensive.

Competency \#3. CREATE. Composing or generating content using creativity and confidence in self-expression, with awareness of purpose, audience, and composition techniques

The challenges that face individuals with disabilities to achieve Competency \#3 can be addressed by embracing and implementing the UDL principle, Multiple Means of Action \& Expression. The guidelines for this principle call for educators to build into their instructional design options for students to show what they know and have learned by providing options for physical action, options for expression and communication, and options for executive functions. To better understand these options, the UDL checkpoints below offer further clarification, with additional details on these checkpoints available on the CAST website:

\section{Options for physical actions}

$>$ Vary and use alternative physical responses

$>$ Vary ways to interact with materials

$>$ Use assistive technologies for access to learning

Options for expressive skills and fluency

$>$ Vary choices for expression of knowledge

$>$ Vary tools for composition and problem solving

$>$ Vary ways to support practice and performance

\section{Options for executive functions}

$>$ Guide and support effective goal setting

$>$ Support goal-related planning and strategy development 
$>$ Use tools to manage information and resources

$>$ Enhance capacity for formative progress self-monitoring (CAST, 2011).

Competency \#4. REFLECT. "Applying social responsibility and ethical principles to one's own identity and lived experience, communication behavior and conduct" (Hobbs, 2010, p. 19).

The challenges that face individuals with disabilities to achieve Competency \#4 can be addressed, in part, by ensuring that access to online learning and social media are both possible and are achieved. Incorporating this competency offers the means for persons with disabilities to connect with others, including persons from differing backgrounds, countries, and perspectives. Individuals can explore their social and ethical beliefs in relationship with differing beliefs. They can reinforce their views by connecting with those who share their priorities and interests. One model of accessibility and UDL in online learning is SOOC4Learning, an online course designed to both teach about UDL and demonstrate UDL in practice through the creative use of Google and other apps. The ways in which this course integrated UDL and supported the varied needs and interests of the participants are documented in the chapter, "Universal Design for Learning (UDL) and Online Learning" in Online Teaching Methods: The Essential Handbook for K-12 Teacher (Perez, Grant, \& Dalton, 2016) and in an earlier article about the SOOC (Dalton, Grant, \& Perez, 2014). Additionally, a free online course "Designing Digital Media for Teaching and Learning," developed by Torrey Trust and students at the University of Massachusetts Amherst can be found at http://blogs.umass.edu/digitalmediacourse/.

Competency \#5. ACT. "Working individually and collaboratively to share knowledge and solve problems in the family, the workplace and the community, and participating as a member of a community at local, regional, national and international levels" (Hobbs, 2010, p. 19).

The challenges that face individuals with disabilities to achieve Competency \#5 are somewhat similar to those encountered in Competency \#4, and the suggestions already provided can certainly be applied here, however other possibilities and resources are also available. With the fast growth of Google Apps and their use in so many areas of education, Google made a serious commitment to the issue of accessibility, and numerous online products and features are currently available through Google Accessibility at https://www.google.com/accessibility. By clicking on Products and Features, a chart appears which outlines accessibility features and resources associated with a wide range of Google products, such as Chrome Browser, Gmail, Google Docs, Google Drive, Google Hangouts, Google Sheets, and even YouTube. Access to these features can facilitate the disabled individual's involvement in social media, and all of the other connection opportunities available through the Google Apps. Access is the most basic step toward self-advocacy and civic action. Without it, those with disabilities cannot participate in their digital communities. Becoming familiar with the wealth of resources available can help to expand educators' 
ability to share knowledge accessibly, and individuals' ability to understand problems and to fully participate in their communities.

\section{Recommendation}

Instructional planning should begin by recognizing and anticipating diversity in all learning environments. By designing instruction and curricula from the start to recognize, honor, and address the full range of learners' natural variation of styles, needs, and preferences, educators can develop, implement, and adjust varied curricula and instructional environments in which barriers have been reduced or, possibly, eliminated. By employing multiple means of representation (including multisensory approaches), multiple means of student expression and actions, multiple ways to engage and motivate learners, and the wide range of features and tools available through technology, it is possible to attain equal access to digital and media literacy for the widest range of learners.

Practical questions regarding UDL implementation and accessibility may remain: What does UDL mean for each educator in their specific environment? How can an organization develop a plan to implement UDL? What evidence exists on the benefits of UDL with digital media? What are potential concerns or problems regarding UDL implementation? While questions remain, the varied needs and abilities of learners demand changes in educational practice, and UDL offers solutions which can address these challenges. Educators of digital and media literacy have much to offer in developing UDL-designed environments; and UDL has much to offer digital and media literacy education through its

principles and guidelines to achieve greater learner access, engagement, and selfefficacy.

\section{References}

American Library Association. (2016). Digital Literacy Definition. Retrieved from http://connect.ala.org/node/181197.

CAST. (2014). Learner Variability and Universal Design for Learning (Video). Retrieved from http://udlseries.udlcenter.org/presentations/learner_variability.html?plist=e xplore.

CAST. (2011). Universal Design for Learning Guidelines version 2.0. Wakefield, MA: Author.

CAST. (2010). UDL and UD Provisions in the Higher Education Opportunity Act (P.L. 110-315). Washington, D.C.: U.S. Department of Education. Retrieved from http://www.udlcenter.org/advocacy/referencestoUDL/HEOA

Center for Universal Design. (1997). What is Universal Design? Retrieved from http://www.design.ncsu.edu/cud/univ_design/ud.htm.

Dalton, E. (2005). Teaching and Learning for All Students Through Differentiated Instruction and Technology. In RI-ASCD Journal of Research and Professional Development: The Leading Edge. V1. Coventry, RI: RIASCD. 
Dalton, E., Grant, K. \& Pérez, L. (2014). SOOC: A New Model for Online Professional Learning Communities Focus: Universal Design for Learning. In Proceedings of World Conference on E-Learning in Corporate, Government, Healthcare, and Higher Education 2014, 19181926. Chesapeake, VA: AACE.

Greene, J., Yu, S., \& Copeland, D. (2014). Measuring Critical Components of Digital Literacy and Their Relationships with Learning. Computers in Education, 76, 55-69.

Hall, T., Strangman, N. \& Meyer, A. (2003). Differentiated Instruction and Implications for UDL Implementation. Wakefield, MA: National Center on Accessing the General Curriculum. Retrieved from http://aim.cast.org/learn/historyarchive/backgroundpapers/differentiated...

Hobbs, R. (2010). Digital and Media Literacy: A Plan of Action. A White Paper on the Digital and Media Literacy Recommendations of the Knight Commission on the Information Needs of Communities in a Democracy. Washington, D.C.: The Aspen Institute.

Meyer, A. \& Rose, D. (1998). Learning to read in the computer age. Cambridge, MA: Brookline Books.

Meyer, A. \& Rose, D. (2005). The Future is in the Margins: The Role of Technology and Disability in Educational Reform. White Paper. American Institutes for Research, U.S. Department of Education, Office of Educational Technology. Wakefield, MA: CAST Inc.

Meyer, Anne and David Rose and David Gordon. 2013. "Universal Design for Learning: Theory and Practice," Wakefield MA: CAST. Retrieved from http://udltheorypractice.cast.org/

National Association for Media Literacy Education. (NAMLE). (2007). Core principles of media literacy education in the United States. Retrieved from https://namle.net/publications/core-principles/

National Association for Media Literacy Education. (NAMLE). (2016). Media Literacy Defined. Retrieved from https://namle.net/publications/medialiteracy-definitions/.

National Center on UDL. (2014). Components of UDL Curriculum. Retrieved from http://www.udlcenter.org/aboutudl/udlcurriculum

Office for Civil Rights. (June, 2006). Your Rights Under Section 504 of the Rehabilitation Act. Revised. Washington, D.C.: US Dept. of Health \& Human Services. Retrieved from www.hhs.gov/sites/default/files/ocr/civilrights/resources/factsheets/504.pd $\mathrm{f}$

Orkwis, R. \& McLane, K. (1998). A Curriculum Every Student Can Use: Design Principles for Student Access. ERIC/OSEP Topical Brief. Reston, VA: ERIC Clearinghouse on Disabilities and Gifted Education. Retrieved from www.eric.ed.gov/PDFS/ED423654.pdf.

Perez, L., Grant, K. \& and Dalton, E. (2016). Universal Design for Learning (UDL) and Online Learning. In Bryans-Bongey, S. \& Graziano, K., (Eds.). Online teaching methods: The essential handbook for K-12 teachers. 
Medford, NJ: Information Today, Inc.

http://books.infotoday.com/books/Online-Teaching-in-K-12.shtml

Rose, D. \& Meyer. A. (2002). Teaching every student in the digital age:

Universal Design for Learning. Alexandria, VA: ASCD.

Rose, D. \& Strangman, N. (2007). Cognition and learning: Meeting the challenge of individual differences. Universal Access in the Information Society, 5(4) 381-391.

Vygotsky, L. (1962). Thought and language. Cambridge, MA: Massachusetts Institute of Technology. 